\title{
A COMPARISON OF BULK CABLE INJECTION TO REVERBERATION CHAMBER METHODS ON A FAULT TOLERANT FLIGHT CONTROL COMPUTER
}

\author{
Daniel M. Koppen, NASA Langley Research Center, Hampton, Virginia
}

\begin{abstract}
The Systems and Airframe Failure Emulation Testing and Integration (SAFETI) Laboratory at the NASA Langley Research Center (LaRC) has been established to study radiated field effects on complex avionics systems and control system components. Established in the first quarter of 2000 , it works hand in hand with the High Intensity Radiated Fields (HIRF) laboratory by using the mode stirred chambers that were constructed and certified during 1995-96.

This paper describes the conducted tests, the data collected, and conclusions derived from comparing the reverberation chamber environment to bulk cable injection technique using a quadredundant flight control computer as a test article. This information will be used to determine if bulk cable injection techniques can be used as a possible alternative to reverberation chambers in pre-testing for radiation fields susceptibility.
\end{abstract}

\section{Open-Loop Experiment Description}

The equipment used to collect the open-loop data [1] is shown as functional blocks in Figure 1. The flight controller consists of four semiindependent modules that contain a 1750 processor, 48 Kbytes of EPROM, 2 Kbytes of local RAM, and 8 Kbytes of shared RAM. Each module can receive sensor inputs and send actuator commands via 35 lines that carry analog voltages or it can receive/send all signals through a digital MIL-STD1553 bus.

The analog signals are interfaced to the flight controller using 9 shielded cable bundles that are about $31 / 2$ meters long. Each line has a pair of passive filters at the connections to the flight controller and the electro/optical converter to reduce noise on the signal lines. The analog electro/optical converter is a custom built circuit that converts all of the analog signals and commands from the flight controller into light which can be transmitted down 9 single-fiber optic lines. This permits a safe, noise-free method of transferring signals in and out of the electromagnetic containment chamber.

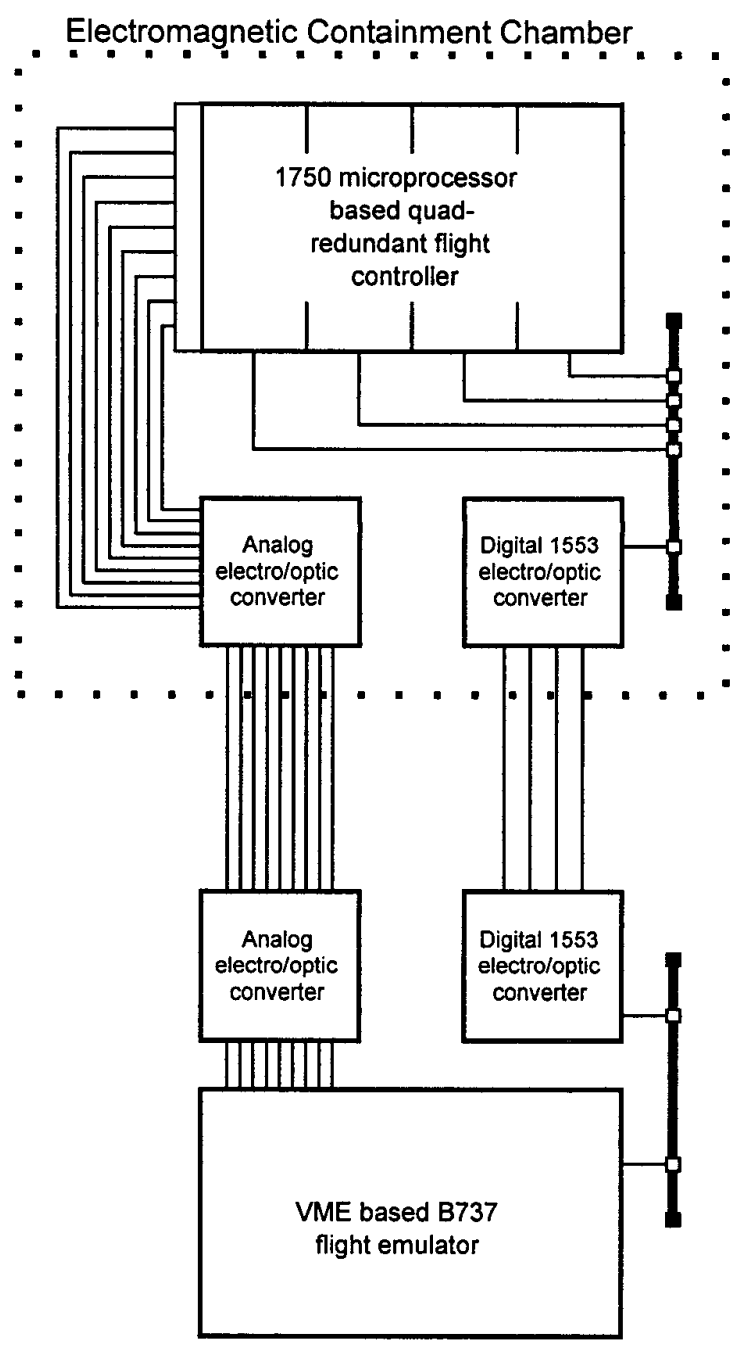

Figure 1. Equipment Setup

\section{U.S. Government work not protected by U.S. Copyright.}

\section{B.4-1}


The MIL-STD-1553 bus consists of four coaxial lines, which are bussed into a fiber optic converter, which also allows safe transfer of the digital signals from the chamber.

The flight emulator hardware is based on a 20 slot VME backplane. The system consists of a PowerPC based controller, five digital to analog converters (DACs), an analog to digital converter (ADC), a MIL-STD-1553 interface board, and a SCRAMnet interface board. The five DACs and the ADC link the emulator to the analog electro/optical converter. Even with five DACs and an $\mathrm{ADC}$, only a single set of $\mathrm{I} / \mathrm{O}$ lines can be driven, so the analog electro/optical converter performs an additional splitting function so that all four of the flight controller's modules receive the same signals.

The electromagnetic containment chambers are two large reverberation chambers located in the High Intensity Radiated Fields Laboratory at LaRC [2]. The first is a $13 \times 23 \times 9 \frac{1}{2}$ foot mode-stirred reverberation chamber that is used much like a large microwave oven that provides a near homogeneous radiation environment. This allows the equipment under test to be exposed to radiation from all angles simultaneously. The second measures $24 \times 48 \times 9$ $1 / 2$ feet and is a larger version of the first, however, only the bulk cable injection methods are tested here, so the chamber is reduced in function to a shielded enclosure.

\section{Special Setup Conditions}

For open-loop experiments, two special conditions are implemented. First, the passive filters were selectively removed. This allows electromagnetic energy to be coupled into the quadredundant flight control computer. These filters are extremely efficient at keeping the flight controller radiation tight, so by removing specific combinations, the flight controller was weakened to the radiated energy. These combinations are shown in Table 1.

The second special condition was that the B737 emulation was removed and the flight emulator hardware was reprogrammed with a special calibration procedure. This procedure sent pre-selected reference voltages to each module in the quad-redundant flight control computer via the analog lines. The flight controller then sent the

Table 1. Filter Removal Combinations

\begin{tabular}{|c|c|}
\hline Filters Removed & Test Objective \\
\hline $1 \& 5$ & Weaken Module A \\
\hline $2 \& 6$ & Weaken Module B \\
\hline $3 \& 7$ & Weaken Module C \\
\hline $4 \& 8$ & Weaken Module D \\
\hline
\end{tabular}

values of the received voltages back to the flight emulator via the MIL-STD-1553 digital signal bus. The flight emulator calibration program then stored the voltage value sent and each flight controller's module received voltage value in memory.

Three reference voltages were calculated for each signal line. They were 1) $50 \%$ of the maximum specified voltage for that signal, 2) zero, and 3) $50 \%$ of the minimum specified voltage for that signal. For example, if the a voltage line is specified to range from plus or minus ten volts, the three voltages sent from the calibration program to the quad-redundant flight control computer would be $+5.0,0$, and -5.0 volts, respectively. These values were calculated for each of the 35 analog signal lines and are held by the calibration program until the quad-redundant flight control computer could take 1,000 samples. Figure 2 shows the algorithm for the automated calibration program. After all 4 runs have been completed, one for each filter combination, the files are transferred to a Windows NT computer for file storage and post analysis.

\section{Reverberation Chamber Setup Conditions}

Once the nominal characterization data had been collected, the quad-redundant flight control computer, analog electro/optical converter, and digital electro/optical converter were placed in the reverberation chamber. Testing started at $250 \mathrm{MHz}$ and was incremented by $100 \mathrm{MHz}$ steps until reaching maximum of $450 \mathrm{MHz}$. Field strength was incremented as shown in Table 2. 


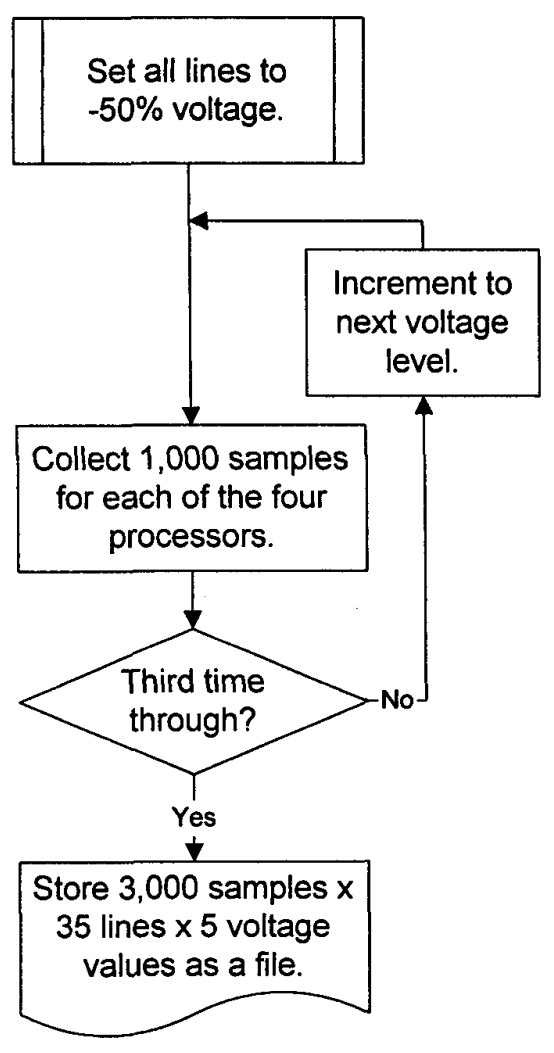

Figure 2. Open-Loop Calibration Algorithm

Table 2. Reverberation Chamber Frequency/Field Strength Combinations

\begin{tabular}{|c|c|c|c|}
\hline & $250 \mathrm{MHz}$ & $350 \mathrm{MHz}$ & $450 \mathrm{MHz}$ \\
\hline $50 \mathrm{~V} / \mathrm{m}$ & $\mathrm{X}$ & $\mathrm{X}$ & \\
\hline $100 \mathrm{~V} / \mathrm{m}$ & $\mathrm{X}$ & $\mathrm{X}$ & $\mathrm{X}$ \\
\hline $150 \mathrm{~V} / \mathrm{m}$ & $\mathrm{X}$ & $\mathrm{X}$ & \\
\hline $200 \mathrm{~V} / \mathrm{m}$ & $\mathrm{X}$ & $\mathrm{X}$ & $\mathrm{X}$ \\
\hline
\end{tabular}

Frequency/field strength combinations were held within the chamber until all 3,000 voltage readings were taken. The flight controller was then powered down, and the reverberation chamber was taken to the next field strength. No readings were taken below $250 \mathrm{MHz}$ because of the reverberation chamber size and no readings above $450 \mathrm{MHz}$ were considered because this was beyond the bulk injection probes specification. Only two readings were taken at $450 \mathrm{MHz}$ due to time constraints.

\section{Bulk Cable Injection Setup Conditions}

Nominal characterization data is collected in this part of the experiment, by setting up the hardware as shown in Figure 3.

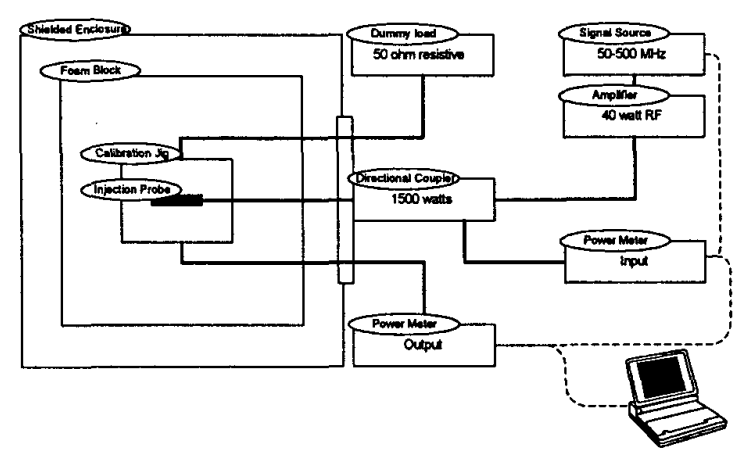

Figure 3. Open-Loop Calibration Setup

A calibration jig is placed in a shielded enclosure with a current injection probe placed inside. The jig is assumed to be a section of 50ohm coax cable and the injection probe encircles the center conductor. Fifty-ohm resistive loads are attached to each side of the jig, with one side being terminated by a power meter. The current injection probe, which is inside the jig, is driven by a signal generator/power amplifier combination. A directional coupler measures the amount of forward power going into the probe. Reflected power is not measured, however voltage standing wave ratios of less then 1.1 were observed in spot checks.

The objective of the calibration process is to measure the amount of forward power required to induce a target output power. The target frequency/output power combinations are shown in Table 3. This procedure is very similar to what is outlined in RTCA/DO-160D Section 20 [3] for bulk cable injection susceptibility testing, with the following exceptions.

Instead of a suspending the quad-redundant flight control computer above a conductive ground plane, the jig and all associated signal lines were 
suspended on a non-conductive surface. It was felt that this would yield a more uniform field and give higher repeatability to the experiment.

Table 3. Bulk Injection Calibration Frequency/Output Current Combinations

\begin{tabular}{|c|c|c|c|c|}
\hline $\begin{array}{c}\text { Target } \\
\text { Power }\end{array}$ & $\begin{array}{c}150 \\
\text { MHz }\end{array}$ & $\begin{array}{c}250 \\
\text { MHz }\end{array}$ & $\begin{array}{c}350 \\
\text { MHz }\end{array}$ & $\begin{array}{c}450 \\
\text { MHz }\end{array}$ \\
\hline $24.490 \mathrm{dBm}$ & $X$ & $X$ & $X$ & $X$ \\
\hline $30.511 \mathrm{dBm}$ & $X$ & $X$ & $X$ & $X$ \\
\hline $34.033 \mathrm{dBm}$ & $\mathrm{X}$ & $\mathrm{X}$ & $\mathrm{X}$ & \\
\hline $36.532 \mathrm{dBm}$ & $\mathrm{X}$ & $\mathrm{X}$ & $\mathrm{X}$ & \\
\hline $38.470 \mathrm{dBm}$ & $\mathrm{X}$ & $\mathrm{X}$ & $\mathrm{X}$ & \\
\hline $\mathbf{4 0 . 0 5 3 \mathrm { dBm }}$ & $\mathrm{X}$ & $\mathrm{X}$ & & \\
\hline $\mathbf{4 1 . 3 9 2} \mathrm{dBm}$ & $\mathrm{X}$ & & & \\
\hline
\end{tabular}

In addition, instead of using target currents as specified in the DO-160D specification, power was used. Once again the thinking was that as the inevitable impedance imbalances that occur when the quad-redundant flight control signal lines are introduced, maintaining power levels would yield more repeatable results.

The power values in Table 3 were calculated using the following formula.

$$
d B m=10 * \log _{10} \frac{(m A)^{2} * 50}{.001}
$$

The currents that were used came from an implied relation between target current and radiated field strength that was found in Figure 20-6 of the RTCA/DO-160D Section 20 [3]. This linear relation approximately follows the equation.

$$
V / m=\frac{m A}{1.5}
$$

The upper limit of this relationship is only constrained by the physical limit of the signal source/power amplifier being used. Through the course of the calibration procedure, the signal was monitored and the test was aborted when any distortion was detected.
Using the above equations, an approximate correlation can be established between radiated fields in a reverberation chamber and the induced power on a cable assembly using bulk cable injection techniques. These relationships are tabulated in Table 4.

Table 4. Calculated Relationships Between Bulk Cable Injection And Radiated Fields

\begin{tabular}{|c|c|c|}
\hline $\begin{array}{c}\text { Bulk } \\
\text { Injection } \\
\text { Target } \\
\text { Power }\end{array}$ & $\begin{array}{c}\text { Desired Bulk } \\
\text { Injection } \\
\text { Induced } \\
\text { Current }\end{array}$ & $\begin{array}{c}\text { Approximate } \\
\text { Equivalent } \\
\text { Radiated Field } \\
\text { Strength }\end{array}$ \\
\hline $24.490 \mathrm{dBm}$ & $75 \mathrm{~mA}$ & $50 \mathrm{~V} / \mathrm{m}$ \\
\hline $30.511 \mathrm{dBm}$ & $150 \mathrm{~mA}$ & $100 \mathrm{~V} / \mathrm{m}$ \\
\hline $34.033 \mathrm{dBm}$ & $225 \mathrm{~mA}$ & $150 \mathrm{~V} / \mathrm{m}$ \\
\hline $36.532 \mathrm{dBm}$ & $300 \mathrm{~mA}$ & $200 \mathrm{~V} / \mathrm{m}$ \\
\hline $38.470 \mathrm{dBm}$ & $375 \mathrm{~mA}$ & $250 \mathrm{~V} / \mathrm{m}$ \\
\hline $40.053 \mathrm{dBm}$ & $450 \mathrm{~mA}$ & $300 \mathrm{~V} / \mathrm{m}$ \\
\hline $41.392 \mathrm{dBm}$ & $525 \mathrm{~mA}$ & $350 \mathrm{~V} / \mathrm{m}$ \\
\hline
\end{tabular}

As shown in Figure 4, spacers were used to maintain the current injection probe's position within the calibration jig. Also shown is the

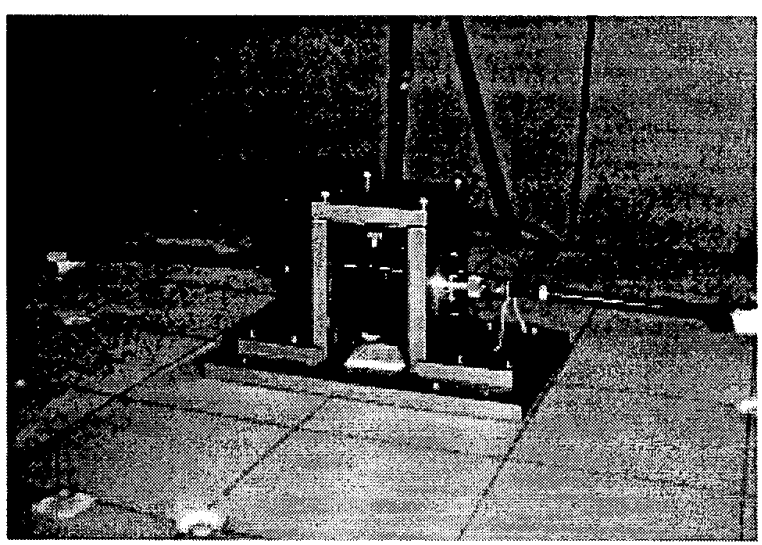

Figure 4. Calibration Jig And Current Injection Probe Within Shielded Enclosure 
styrofoam block used to suspend the assembly on a non-conductive surface.

After the required inputs to achieve the target outputs had been recorded, the experiment is reconfigured as shown in Figure 5. The calibration jig is removed and the quad-redundant flight control computer and the electro/optical converters are installed. Each cable bundle is then routed through the current injection probe and the appropriate filter set is removed. Figure 6 shows the actual testing conditions within the shielded enclosure.

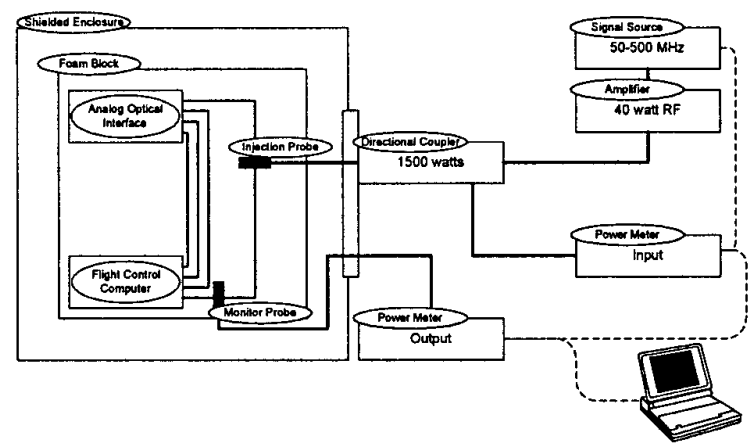

Figure 5. Open-Loop Test Configuration

After the input frequency and power have been set to the value required, the algorithm described in Figure 2 is run and the data collected. During the period of time the injection probe is active and the algorithm is running, a probe physically located near the quad-redundant flight control computer's input connector monitors the current levels for possible over-current conditions.

Coordination of the dual activities of applying the fields and starting the algorithm proved difficult, and in the first attempt the algorithm initiated before the field was applied. All the data from this attempt was purged with the exception of the current monitoring information. No anomalies were detected in over three days of testing and to minimize any extraneous filtering, the monitor probe was removed in subsequent tests.

\section{Data Analysis}

Open-loop experimental history would suggest that a realistic approach to quantizing the data collected, would be to examine the standard deviation of the received voltages for each frequency / power / filter / signal combination. The

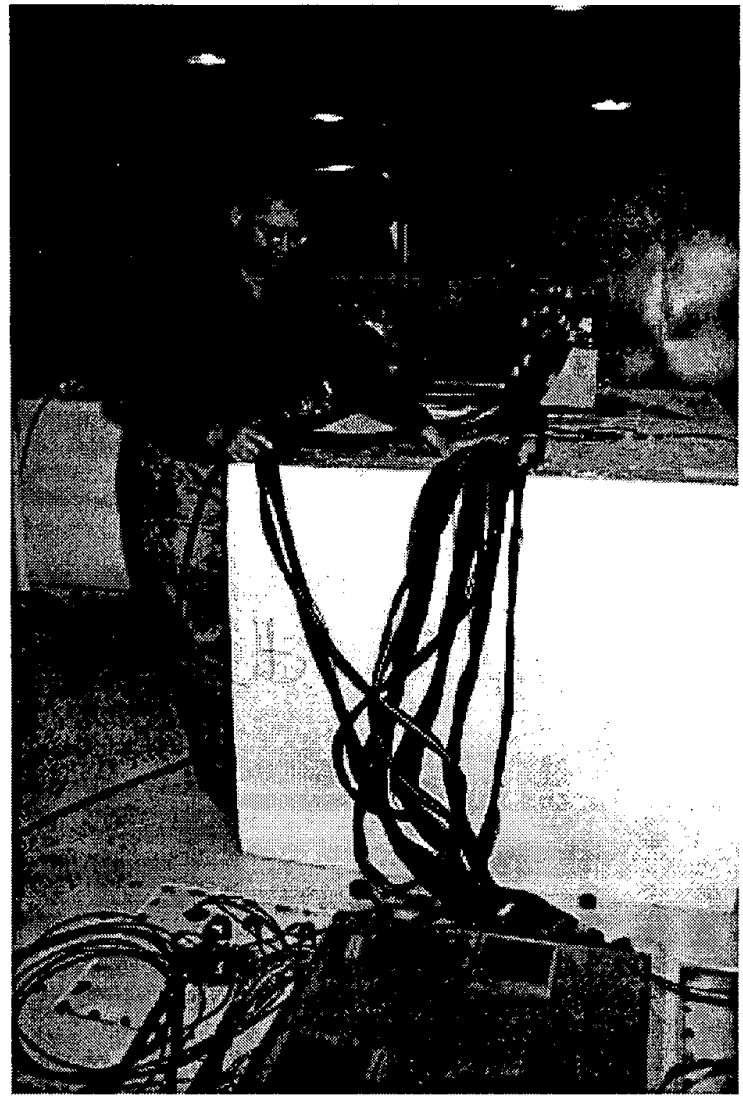

Figure 6. Open-Loop Test Layout Within Shielded Enclosure

electromagnetic effect described in Determination of Upper Destructive limit for HIRF Experiments on a Fault Tolerant Flight Control Computer, [4] indicated that independent of the frequency being applied, signal degradation increased as field strength rose. Statistically, this should manifest itself as an increase in the standard deviation on each unfiltered received signal voltage as the electromagnetic field strength is increased. In addition, if the remaining passive filters are effective, the parallel signal lines should show no discernible change in their respective standard deviations.

Although all of the data is available and has been analyzed, for the purposes of this paper, only a limited set of signals will be discussed. These will be the Calibrated Air Speed (CAS), Yaw Rate (RBdgs), and Track (TK) signal lines on modules two and four of the quad-redundant flight control computer. These signal lines were selected because 
they represent the widest range of voltage specifications as shown on Table 5. Modules (cells in Figures 7-22) two and four were selected because of their physical location within the flight control computer. Module two is an inner cell with

Table 5. Reference Voltage Levels for Representative Signal Lines

\begin{tabular}{|c|c|c|c|}
\hline $\begin{array}{c}\text { Reference } \\
\text { Voltage }\end{array}$ & CAS & RBdgs & TK \\
\hline$-50 \%$ & $-0.575 \mathrm{~V}$ & $-2.5 \mathrm{~V}$ & $-5.0 \mathrm{~V}$ \\
\hline 0 & $0 \mathrm{~V}$ & $0 \mathrm{~V}$ & $0 \mathrm{~V}$ \\
\hline$+50 \%$ & $+0.575 \mathrm{~V}$ & $+2.5 \mathrm{~V}$ & $+5.0 \mathrm{~V}$ \\
\hline
\end{tabular}

maximum natural shielding and module four is located on one end of the box and might be less protected.

\section{Reverberation Chamber Results}

Figures 7 through 14 show the standard deviation results for the data collected in the HIRF

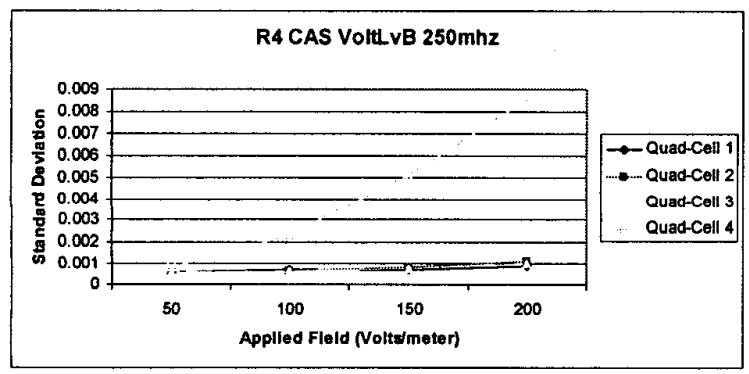

Figure 7. Results For CAS Signal At $250 \mathrm{Mhz}$ Radiated Field, Module 4

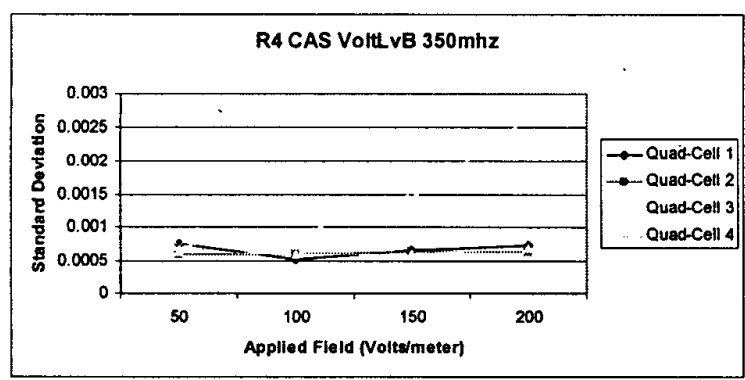

Figure 8. Results For CAS Signal At $350 \mathrm{Mhz}$ Radiated Field, Module 4

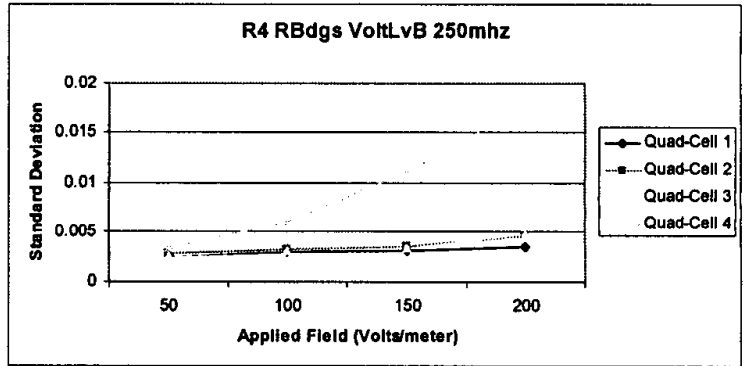

Figure 9. Results For Rbdgs Signal At $250 \mathrm{Mhz}$ Radiated Field, Module 4

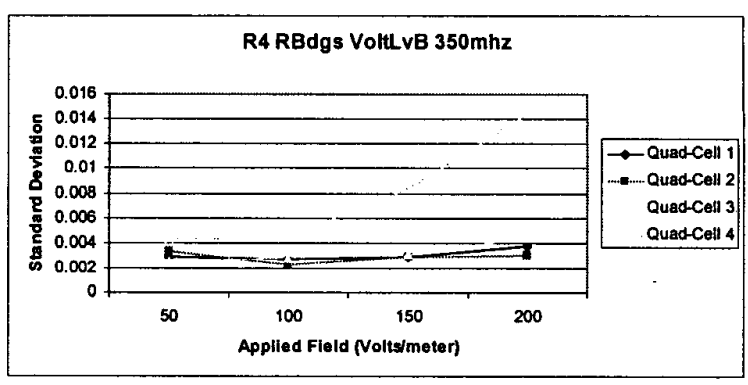

Figure 10. Results For Rbdgs Signal At $350 \mathrm{Mhz}$ Radiated Field, Module 4

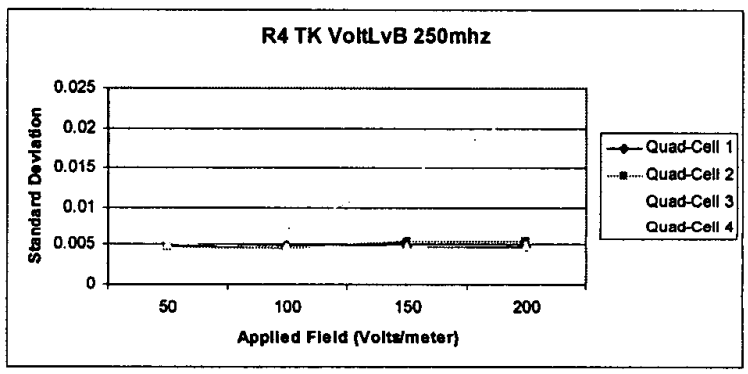

Figure 11. Results For TK Signal At $250 \mathrm{Mhz}$ Radiated Field, Module 4

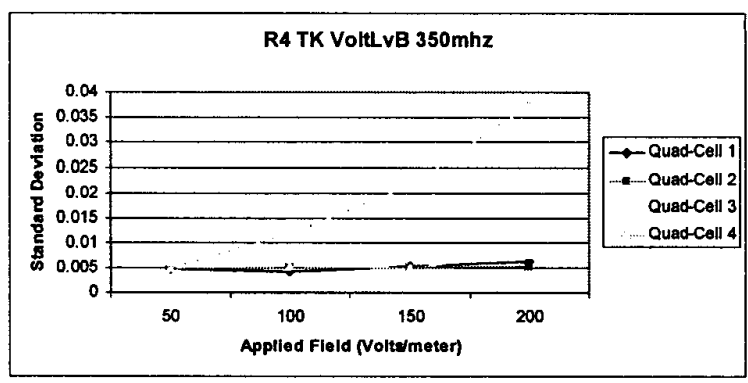

Figure 12. Results For TK Signal At $350 \mathrm{Mhz}$ Radiated Field, Module 4 


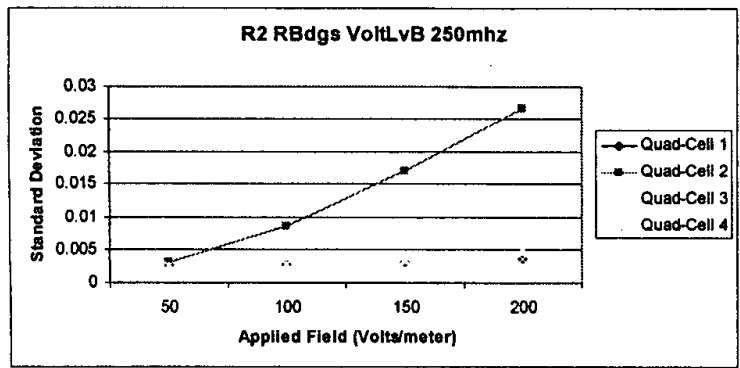

Figure 13. Results For Rbdgs Signal At 250 Mhz Radiated Field, Module 2

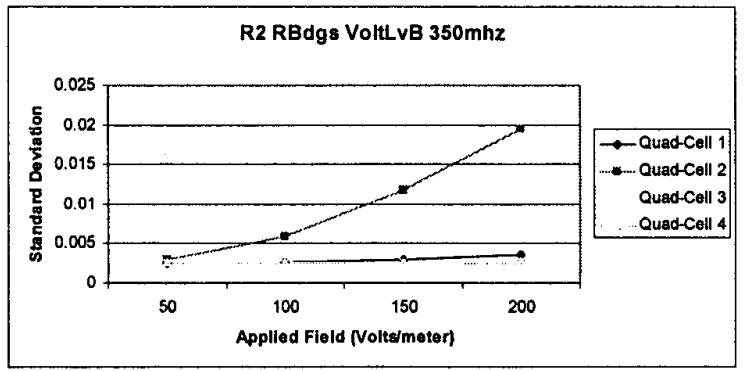

Figure 14. Results For Rbdgs Signal At 350 Mhz Radiated Field, Module 2

laboratory's reverberation chamber. In each case, the unfiltered signal line undergoes progressive signal degradation and all of the filtered signals maintain their integrity as the applied field is increased.

\section{Bulk Cable Injection Results}

Figures 15 through 22 show the standard deviation results for the data collected using the bulk cable injection procedure. No discernible signal degradation is observed on any of the signals.

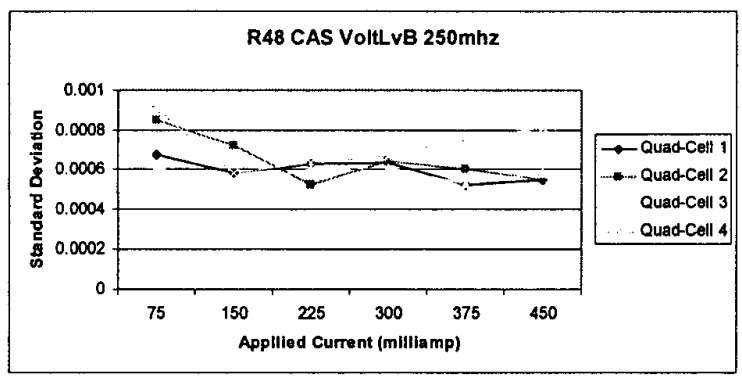

Figure 15. Results For CAS Signal At 250 Mhz Bulk Cable Injection, Module 4

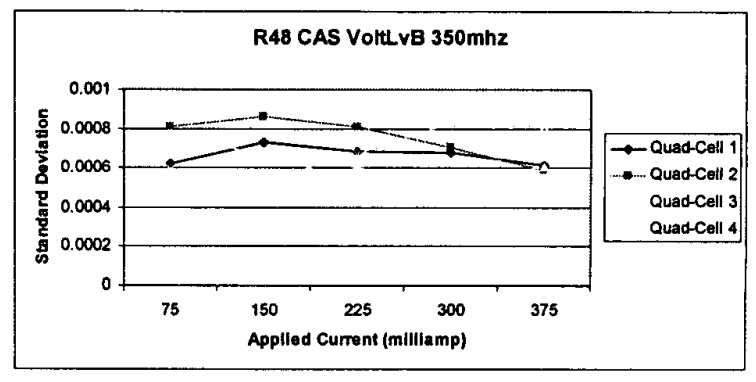

Figure 16. Results For CAS Signal At $350 \mathrm{Mhz}$ Bulk Cable Injection, Module 4

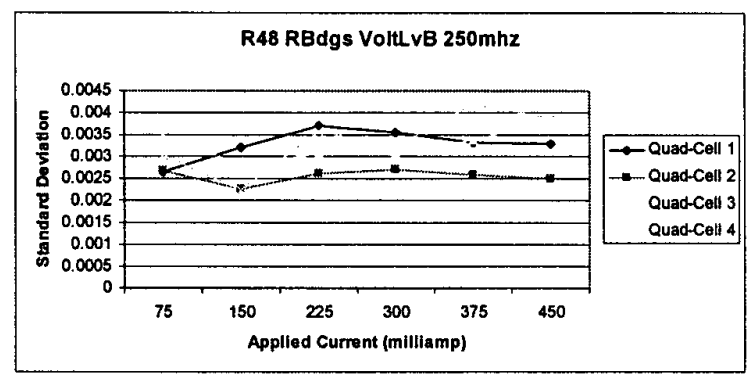

Figure 17. Results For Rbdgs Signal At 250 Mhz Bulk Cable Injection, Module 4

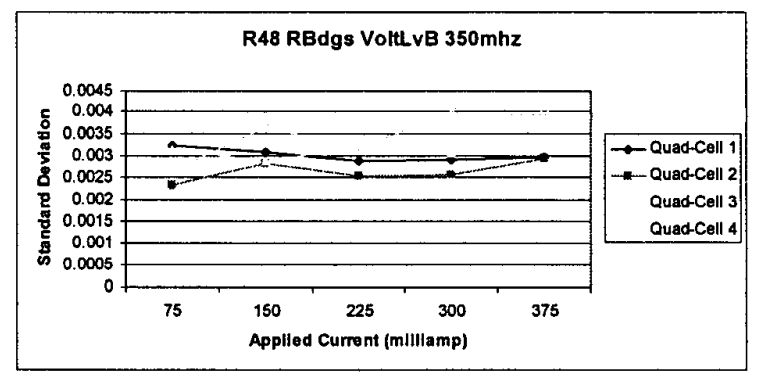

Figure 18. Results For Rbdgs Signal At $350 \mathrm{Mhz}$ Bulk Cable Injection, Module 4

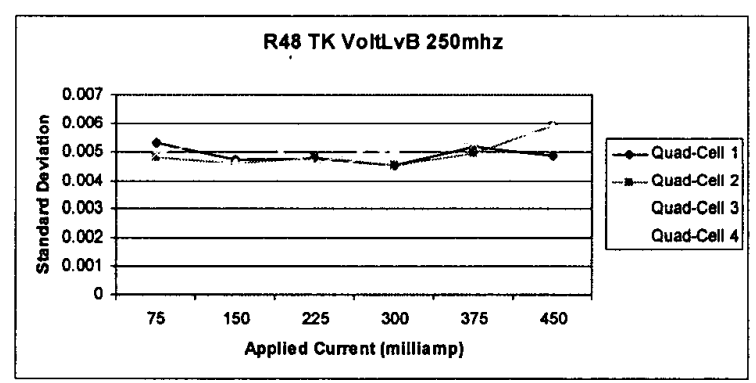

Figure 19. Results For TK Signal At $250 \mathrm{Mhz}$ Bulk Cable Injection, Module 4 


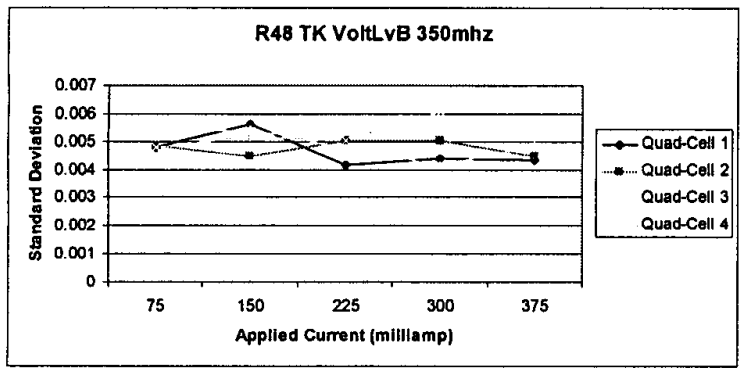

Figure 20. Results For TK Signal At 350 Mhz Bulk Cable Injection, Module 4

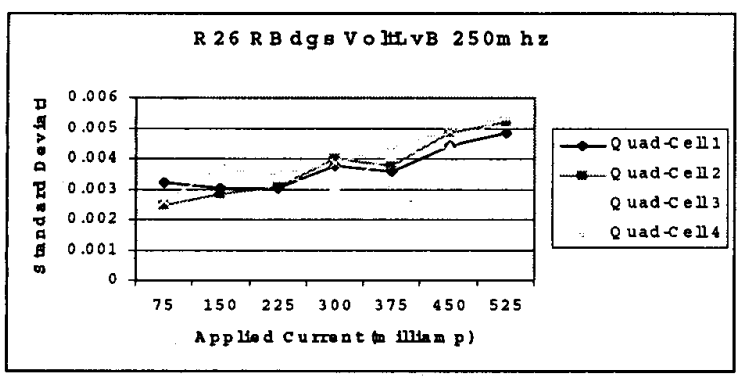

Figure 21. Results For Rbdgs Signal At $250 \mathrm{Mhz}$ Bulk Cable Injection, Module 2

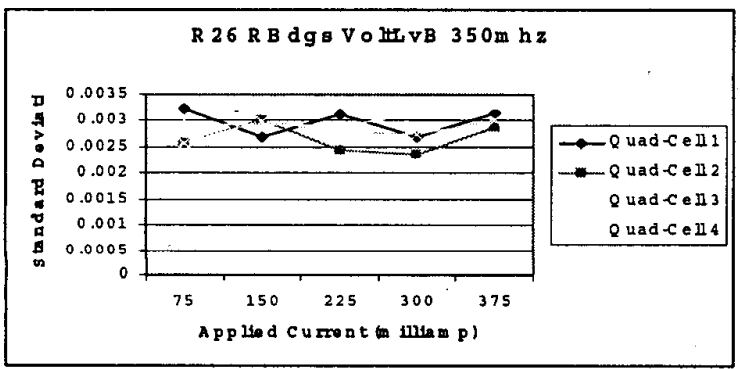

Figure 22. Results For Rbdgs Signal At 350 Mhz Bulk Cable Injection, Module 2

\section{Conclusions}

After observing the effects that the reverberation chamber had on the quad-redundant flight control computer's analog signals, it was widely assumed that with the removal of the filter, each signal line became a virtual receiving antenna that allowed the electromagnetic field to flow unrestricted into the flight control computer. Though each signal is transmitted on a coaxial cable that is well grounded on the electro/optical converter even without the filter installed, the sharp contrast between the filtered and unfiltered lines within the reverberation chamber certainly tended toward that theory. However, the bulk cable injection data shows that the signal degradation observed in the reverberation chamber could not be repeated, when the signal lines were subjected to the current injection probe's localized field.

Reevaluation of the power levels used and their correlation to the reverberation chamber's field levels will be examined. In addition, powercoupling differences between the two techniques will be explored. Until these differences can be resolved, all future testing for electromagnetic susceptibility on aircraft digital avionics within the SAFETI lab will make use of the HIRF lab's reverberation chambers.

\section{References}

[1] Koppen, Daniel M., 1997, Open-Loop HIRF Experiments Performed on a Fault Tolerant Flight Control Computer, AIAA/IEEE $16^{\text {th }}$ DASC

Proceedings.

[2] Williams, Rueben A., 1997, The NASA HighIntensity Radiated Fields Laboratory, AIAA/IEEE $16^{\text {th }}$ DASC Proceedings.

[3] Radio Technical Commission for Aeronautics Document, RTCA DO-160D, Section 20, 1997, Environmental Conditions and Test Procedures for Airborne Equipment.

[4] Smith, Laura J., Koppen, Daniel M., 1998, Determination of Upper Destructive Limit for HIRF Experiments on a Fault Tolerant Flight Control Computer, AIAA/IEEE $17^{\text {th }}$ DASC Proceedings.

\section{Acknowledgments}

The author of this paper is grateful for the contributions of many other Systems and Airframe Failure Emulation Testing and Integration Laboratory team members particularly, Dr. Celeste M. Belcastro, the SAFETI team leader, and B. Weinstein, the SAFETI team program analyst. In addition, a special thanks to Truong Nguyen of the NASA High-Intensity Radiated Fields team who's technical advice was essential to this project. 